\title{
Latent and subclinical tuberculosis in HIV infected patients: a cross-sectional study
}

\author{
Meaghan M Kall ${ }^{1,4^{*}}$, Katherine M Coyne ${ }^{1}$, Nigel J Garrett ${ }^{1}$, Aileen E Boyd ${ }^{3}$, Anthony T Ashcroft $^{2}$, lain Reeves ${ }^{1}$, \\ Jane Anderson ${ }^{1}$ and Graham H Bothamley ${ }^{3}$
}

\begin{abstract}
Background: HIV and tuberculosis (TB) are commonly associated. Identifying latent and asymptomatic tuberculosis infection in HIV-positive patients is important in preventing death and morbidity associated with active TB.

Methods: Cross-sectional study of one time use of an interferon-gamma release assay (T-SPOT.TB - immunospot) to detect tuberculosis infection in patients in a UK inner city HIV clinic with a large sub-Saharan population.

Results: 542 patient samples from 520 patients who disclosed their symptoms of TB were tested. Median follow-up was 35 months (range 27-69). More than half (55\%) originated from countries with medium or high tuberculosis burden and 57\% were women. Antiretroviral therapy was used by 67\%; median CD4 count at test was 458 cells/ $\mu$ l. A negative test was found in 452 samples and an indeterminate results in 40 (7.4\%) but neither were associated with a low CD4 count. A positive test was found in 10\% (50/502) individuals. All patients with positive tests were referred to the TB specialist, 47 (94\%) had a chest radiograph and 46 (92\%) attended the TB clinic. Two had culture-positive TB and a third individual with features of active TB was treated. 40 started and 38 completed preventive treatment. One patient who completed preventive treatment with isoniazid monotherapy subsequently developed isoniazid-resistant pulmonary tuberculosis. No patient with a negative test has developed TB.

Conclusions: We found an overall prevalence of latent TB infection of 10\% through screening for TB in those with HIV infection and without symptoms, and a further $1 \%$ with active disease, a yield greater than typically found in contact tracing. Acceptability of preventive treatment was high with $85 \%$ of those with latent TB infection eventually completing their TB chemotherapy regimens. IGRA-based TB screening among HIV-infected individuals was feasible in the clinical setting and assisted with appropriate management (including preventive treatment and therapy for active disease). Follow-up of TB incidence in this group is needed to assess the long-term effects of preventive treatment.
\end{abstract}

\section{Background}

In 1998, the World Health Organization recommended detection of latent tuberculosis infection (LTBI) in HIV infected individuals in order to institute preventive treatment [1]. Currently, in resource constrained settings, isoniazid preventive therapy is recommended for those likely to have LTBI, but research is required to evaluate the role of tests to identify tuberculosis (TB) and LTBI [2]. Interferon-gamma release assays (IGRAs) have a higher sensitivity in patients with lower CD4 counts and

\footnotetext{
* Correspondence: meaghan.kall@hpa.org.uk

'Department of Sexual Health, Homerton University Hospital, Homerton Row, London E9 6SR, United Kingdom

${ }^{4}$ HIV and STI Department, Health Protection Services - Colindale, Health Protection Agency, 61 Colindale Avenue, London NW9 5EQ, United Kingdom Full list of author information is available at the end of the article
}

greater specificity in those from areas with a low incidence of TB than the tuberculin skin test; although in active disease the sensitivity is still about $80 \%$ [3]. The T-SPOT ${ }^{\circledR} . T B$ (immunospot) assay may have a higher sensitivity with fewer indeterminate results in immunosuppressed patients than the QuantiFERON-TB Gold [3]. This may be because the immunospot uses a fixed number of peripheral blood mononuclear cells and should therefore be less affected by the CD4 lymphocyte count.

In low TB burden countries, the role of IGRAs in screening HIV infected individuals has yet to be established. The United States Center for Disease Control guidelines advocate testing for LTBI at HIV diagnosis regardless of TB risk category [4] whereas UK national guidelines suggest an approach based on region of origin, CD4 count and length of time on antiretrovirals [5]. However, there are limited

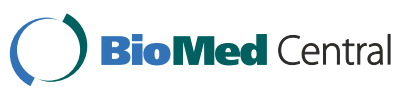


data on the utility of IGRAs as a screening tool in a low incidence clinical setting and on the management of positive results [6-8].

Homerton University Hospital is situated in Hackney, London with an HIV prevalence five times the national average (825 versus 164 per 100,000 population) [9], and annual TB incidence four times the national average (58 versus 15 per 100,000 population) [10]. The area has high numbers of migrants from sub-Saharan Africa. Over a third of the HIV patient cohort is from high tuberculosis burden countries, as defined by WHO criteria [11]. Approximately two thirds were diagnosed with HIV at a late stage of infection $(\mathrm{CD} 4<350$ cells $/ \mu \mathrm{l})$. The aims of this study were to evaluate the use of an IGRA in screening for latent or symptomless active TB in a cohort of patients with HIV infection, and to determine the completion rate of preventive treatment in patients with positive tests.

\section{Methods}

\section{Study population, design, and entry criteria}

All patients $(\sim 600)$ attending the HIV outpatient clinic at Homerton University Hospital from April 2006 until October 2009 were eligible for screening, except those who were currently being investigated or treated for active $\mathrm{TB}$ and patients who ever received treatment for suspected or confirmed TB $(n=93)$. Recruitment was carried out in two phases. In phase one (April 2006 to April 2008) the immunospot assay was offered one day per week as a pilot study funded by the Department of Health, the results of which have been reported in an abstract [12]. In phase two, the Primary Care Trust agreed to expand screening to the remaining cohort as part of standard clinical care. Informed consent was obtained from patients who took part in the initial pilot study. Patients were asked whether they had cough, fever, night sweats or weight loss, as recommended by the WHO screening program [13]. The number of $\mathrm{HIV} / \mathrm{TB}$ coinfected individuals treated at this hospital provided the denominator to measure the effect of screening.

\section{Immunospot assay}

Venous blood samples were drawn and transported to the hospital microbiology laboratory on the day of collection. The T-SPOT ${ }^{\circledR}$.TB assay (Oxford Immunotec, Oxford, UK) is a commercially available enzyme-linked immunospot assay which uses a fixed number of peripheral blood mononuclear cells. Blood samples were processed using standard operating procedure OXIM. SOP06-001. Positive and negative controls were included to validate the result. A result was considered positive if the number of spot-forming cells obtained from test antigens was more than twice the number of the negative control and had six or more spots than the negative control. Wherever possible, patients with indeterminate results had a second sample tested.

\section{Clinical management of patients with positive result}

Patients with positive results were referred to a TB specialist physician. All patients had a further symptom assessment, chest radiograph, and sputum (three samples if productive or at least one induced sputum with hypertonic 3\% saline) sent for smear microscopy and mycobacterial culture. Further investigations were carried out in line with clinical findings. Referral to the TB specialist was delayed for three months for individuals commencing highly active antiretroviral therapy (HAART) to observe symptoms of TB that might emerge as a result of immune reconstitution.

The decision to initiate preventive treatment was made by the TB physician after discussion with the patient regarding the risks and benefits. Patients on HAART were offered six months of isoniazid as recommended in national guidelines [14]. Those not on HAART had the option of three months rifampicin and isoniazid [15]. Without HAART, rifampicin posed no risk of drug interactions and patients could be involved in the choice of treatment, a process which enhances adherence [16]. Where active tuberculosis was suspected, two months of rifampicin, isoniazid and pyrazinamide were given, with or without ethambutol depending on clinical suspicion and likelihood of drug-resistance $[17,18]$. If active infection was proven or likely from the response to treatment (i.e. weight gain, resolution of radiographic changes), the standard six month anti-tuberculosis regimen was continued or modified according to drug sensitivities. If active TB was ultimately excluded, the regimen of two months rifampicin and pyrazinamide was considered sufficient preventive treatment [15]. In severely immunosuppressed patients, TB prophylaxis was continued until CD4 $>200$ cells/ $\mu \mathrm{l}$ [19]. Those declining to attend the TB clinic were offered follow-up and preventive treatment in the HIV clinic.

\section{Data handling and statistical analysis}

Patient details including age, sex, ethnicity, country of origin, CD4 count at test and receipt of antiretroviral therapy were collected. The Shapiro-Wilk test was used to test for normality of continuous variables. Differences in proportions of categorical variables were tested using $X^{2}$ test, and differences in median values of continuous variables were tested using the Kruskal-Wallis test. Univariate analysis was performed using logistic regression. Odds ratio and 95\% confidence interval (OR, 95\% CI) were used to measure the association between different variables and immunospot result. All statistical calculations were performed using STATA (Stata Statistical 
Software: Release 11. College Station, TX: StataCorp LP. 2009).

\section{Ethics}

Ethical approval for the pilot study was granted by Multicentre Research Ethics Committee and the East London and City Health Authority (P/03/285: Blood tests for tuberculosis).

\section{Results}

\section{Patient characteristics}

Over half (57\%) of the cohort were women and 55\% were patients from medium or high prevalence $\mathrm{TB}$ countries (30-300 and $>300$ cases per 100,000 population, respectively, Table 1). 542 blood samples were collected from 520 patients (138 patients in the pilot study and 382 in the expanded phase, including 22 patients who had repeat samples tested after their first sample gave an indeterminate result). The immunospot assay yielded 452 negative results, 50 positive results, and 40 indeterminate results (Figure 1).

Table 1 Characteristics of study patients

\begin{tabular}{|c|c|}
\hline Variable & $\begin{array}{l}\text { Patients } \\
(n=520)\end{array}$ \\
\hline \multicolumn{2}{|l|}{ Age (\%) } \\
\hline $15-24$ & $16(3)$ \\
\hline $25-34$ & $138(27)$ \\
\hline $35-44$ & $227(44)$ \\
\hline $45-54$ & $105(20)$ \\
\hline $55+$ & $34(7)$ \\
\hline Female (\%) & $296(57)$ \\
\hline \multicolumn{2}{|l|}{ CD4 count at test (\%) } \\
\hline$<200$ & $55(11)$ \\
\hline 200-349 & $112(21)$ \\
\hline $350+$ & $353(68)$ \\
\hline CD4 cells/ $\mu$ l median (IQR) & $458(312-631)$ \\
\hline Receiving HAART (\%) & $348(67)$ \\
\hline \multicolumn{2}{|l|}{ Ethnicity } \\
\hline White British & $53(10)$ \\
\hline Black African & $334(64)$ \\
\hline Asian & $15(3)$ \\
\hline Black Caribbean & $43(8)$ \\
\hline Other/mixed & $75(14)$ \\
\hline \multicolumn{2}{|c|}{ TB prevalence in country of origin per $100,000(\%)$} \\
\hline Low $(<30)$ & $141(27)$ \\
\hline Medium (30-300) & $92(18)$ \\
\hline $\operatorname{High}(>300)$ & $287(55)$ \\
\hline
\end{tabular}

$\mathrm{IQR}=$ interquartile range.

HAART = highly active anti-retroviral therapy.

\section{Indeterminate and borderline results}

After the first round of testing, 36 patients gave an indeterminate test. Twenty-two patients were retested, of whom 17 were negative, two positive, and four indeterminate for a second time. Thus, out of 542 tests, 40 (7.4\%) were indeterminate. The reasons for an indeterminate test were: 15 samples had a low cell number (too few circulating T-cells to produce interferon-gamma); in 11 the positive control failed; nine had a high background in the negative control panel; three failed to separate cells after centrifugation; and $\mathrm{CO}_{2}$ flow failure affected test performance in two tests. Median CD4 count for the forty indeterminate test results was 503 cells/ $\mu$ l (IQR 401-606), compared to 456 cells/ $\mu \mathrm{l}$ (IQR 310-610) for the 502 determinate (positive or negative) tests. Low CD4 count at test was not associated with an indeterminate result $(\mathrm{p}=0.198)$.

In the United States, the immunospot test has a borderline category, in which those with 5-7 spots are placed [4]. Analysing our data by these criteria, five patients with a negative response would have been classified as borderline - none have since developed TB. A further 5, who were classified as reactive, would have been assigned borderline status, all of whom completed preventive treatment and did not develop TB.

\section{Analysis of positive and negative immunospot results}

A comparison of demographic and clinical characteristics of those with positive and negative results is shown in Table 2. Excluding the 10 with a borderline result did not change any of the significant differences between negative and positive individuals.

Sex, age and the proportion of individuals receiving HAART were similar between the two groups. Subgroup analysis of patients on HAART showed that the mean duration of antiretroviral exposure between positive and negative tests was not significantly different ( 4.1 vs. 3.5 years, $P=0.352$ ).

A higher proportion of patients of black African ethnicity had a positive immunospot result compared to others (13.0\% vs. $4.7 \%)$; however ethnicity was not significant predictor of test outcome in the regression model. Being from a high TB prevalence country (OR, 5.01; 95\% CI, $1.75-14.36 ; P=0.003$ ) or medium TB prevalence country (OR, 3.73; 95\% CI, 1.11-12.52; $P=0.033$ ) were the only significant predictors of a positive immunospot test.

\section{Investigation for active TB}

All fifty patients with positive immunospot tests were referred to the TB specialist. Forty seven (94\%) patients had chest radiographs, 11 of which were abnormal (Table 3). Sputum samples were taken from $30(60 \%)$ patients and included all with an abnormal chest radiograph; the remainder were unable to produce a sample 


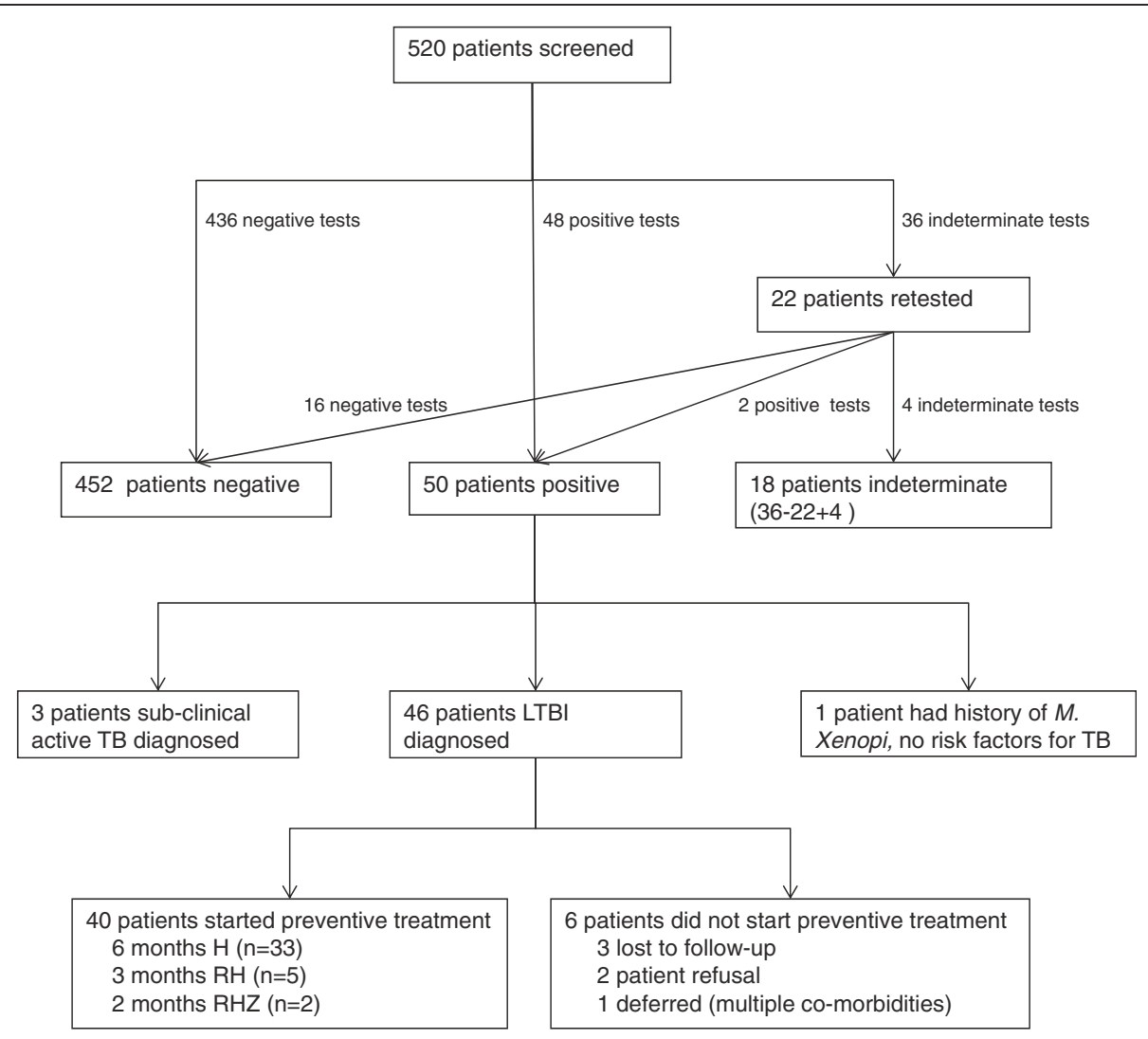

Figure 1 Flow diagram of patients tested with the immunospot test and subsequent diagnosis and treatment of LTBI. TB, tuberculosis; LTBI, latent tuberculosis infection; Drug regimens are abbreviated to the letters for the drugs administered: $H$, isoniazid; R, rifampicin; Z, pyrazinamide.

despite the use of hypertonic saline to induce sputum. Twenty-five patients gave induced sputum samples, four had a productive cough, and one patient with abnormal chest radiography underwent bronchoalveolar lavage.

Three women were diagnosed with subclinical active TB. One individual without any symptoms and a normal chest radiograph had a positive immunospot and sputum culture grew Mycobacterium tuberculosis. Another had previously denied any symptoms, but when questioned more closely after the positive immunospot and abnormal chest $x$-ray, then reported symptoms and was also culture-positive. A third showed significant weight gain after treatment for $\mathrm{TB}$ and did not take any treatment for HIV during the time of the study. Thus, subclinical tuberculosis was detected in $0.6 \%(3 / 502)$ of those who tested and $6 \%(3 / 50)$ of those with a positive result. A positive result was encountered in a patient with $M$. xenopi infection who had no risk factors for exposure to TB. During the same period of study, two patients with symptoms and who were therefore not included in the screening cohort proved to have TB and had a positive immunospot test. During the study period, a total of 33 HIV-infected patients were under treatment for active tuberculosis at the hospital, of which nearly $10 \%(3 / 33)$ had been initially diagnosed through screening the asymptomatic HIV-infected population.

\section{Latent TB infection: prevalence and treatment}

The prevalence of diagnosed latent TB infection was 9.2\% (46/502 i.e. excluding three with active TB and one probably false positive from $M$. Xenopi, out of those patients with a determinate result.) (Figure 1). All except two were offered preventive treatment and 40 (87\%) commenced treatment. Reasons for not starting preventive treatment included non-attendance at appointments (3), patient refusal due to low perceived risk of TB infection (2), and deferral due to multiple co-morbidities (1). Thirty-five patients chose to be managed in the TB clinic and five chose the HIV clinic. To date, 38 (95\%) have completed treatment, one stopped 10 days before completing 6 months treatment with isoniazid and another stopped at 6 months although the CD4 count was 131 cells $/ \mu$ l.

\section{Follow up of incident tuberculosis}

The median duration of follow-up from immunospot testing was 35 months (range 27 - 69 months). No patient with 
Table 2 Univariate analysis of factors associated with a positive immunospot test*

\begin{tabular}{|c|c|c|c|c|}
\hline & \multicolumn{2}{|c|}{ Result } & \multirow{2}{*}{$\begin{array}{c}\text { Odds ratio } \\
\begin{array}{c}\text { (95\% confidence } \\
\text { interval) }\end{array}\end{array}$} & \multirow{2}{*}{$\begin{array}{c}P- \\
\text { value }\end{array}$} \\
\hline & $\begin{array}{l}\text { Negative } \\
(\mathrm{n}=452)\end{array}$ & $\begin{array}{l}\text { Positive } \\
(n=50)\end{array}$ & & \\
\hline \multicolumn{5}{|l|}{ Age } \\
\hline $15-24$ & 14 & 1 & 1 & 0.867 \\
\hline $25-34$ & 117 & 12 & $1.44(0.17-11.80)$ & \\
\hline $35-44$ & 197 & 25 & $1.78(0.22-14.09)$ & \\
\hline $45-54$ & 92 & 10 & $1.52(0.18-12.82)$ & \\
\hline $55+$ & 32 & 2 & $0.87(0.07-10.46)$ & \\
\hline
\end{tabular}

\begin{tabular}{|c|c|c|c|c|}
\hline \multicolumn{5}{|l|}{ CD4 count } \\
\hline$\leq 350$ & 302 & 38 & 1 & 0.368 \\
\hline $200-349$ & 101 & 7 & 0.55 & \\
\hline$<200$ & 49 & 5 & 0.81 & \\
\hline Female (\%) & $255(57)$ & $29(58)$ & $1.06(0.59-1.93)$ & 0.830 \\
\hline HAART (\%) & $304(67)$ & $33(66)$ & $0.94(0.51-1.75)$ & 0.858 \\
\hline \multicolumn{5}{|l|}{ Ethnicity } \\
\hline White British & 49 & 1 & 1 & 0.078 \\
\hline Black African & 282 & 42 & $7.30(0.98-54.26)$ & \\
\hline Asian & 14 & 1 & $3.50(0.21-59.59)$ & \\
\hline Black Caribbean & 39 & 3 & $3.77(0.38-37.67)$ & \\
\hline Other/mixed & 68 & 3 & $2.16(0.22-21.41)$ & \\
\hline \multicolumn{5}{|l|}{ TB prevalence in } \\
\hline \multicolumn{5}{|c|}{$\begin{array}{l}\text { country of origin per } \\
100,000\end{array}$} \\
\hline Low $(<30)$ & 131 & 4 & 1 & \\
\hline Medium (30-300) & 79 & 9 & $3.73(1.11-12.52)$ & 0.033 \\
\hline High (>300) & 242 & 37 & $5.01(1.75-14.36)$ & 0.003 \\
\hline
\end{tabular}

*Analysis includes individuals with borderline results as defined by the CDC, United States [4].

a negative immunospot has developed TB. One patient who had a positive test and was treated with six months isoniazid was subsequently diagnosed with isoniazid-resistant pulmonary TB after two years (Table 3, Patient 10). The patient successfully completed tuberculosis treatment with rifampicin, pyrazinamide, ethambutol, moxifloxacin and streptomycin.

\section{Discussion}

This paper has shown that screening for TB amongst those living with HIV is feasible. Screening showed that about $10 \%$ of our HIV clinic population were latently infected with TB, and three cases of active sub-clinical TB were detected. Screening among those with HIV is as effective as contact tracing, a standard procedure in TB control programs [14]. Since our study, the UK National Institute for Clinical Excellence (NICE) has issued guidelines which recommend IGRA testing for people with
HIV (with CD4 200-500 cells/ $\mu$ l, and alongside a Mantoux test if $\mathrm{CD} 4<200$ cells $/ \mu \mathrm{l}$ ) and, if the test is positive, performing a clinical assessment to exclude TB and consider treating latent TB infection [20]. Our study supports these recommendations, although it is notable that we did not observe the test result to be sensitive to CD4 count.

Various algorithms have been used to detect active TB in those with HIV infection $[21,22]$. Symptom screening has been advocated. However, people living with HIV in South Africa and Zimbabwe also have high rates of active TB even when they are asymptomatic [23,24]. In this study, one patient did not admit to any symptoms until a positive test provoked further direct inquiry. Chest radiography is of limited usefulness and is complicated by atypical presentations and even a normal appearance in 14-23\% of patients with culture-positive pulmonary disease and HIV co-infection [25,26]. A study in Tanzania found that of asymptomatic HIV-infected adults (CD4 >200, no TB symptoms and a normal chest radiograph), 5\% had active TB diagnosed on positive sputum cultures [27]. Sputum examination is used, especially in areas of high TB incidence to detect active TB in those with HIV infection. A recent meta-analysis found that intensified case finding with microbiological investigation (sputum smear or culture) in all patients, irrespective of symptoms, detected an additional four TB cases per $100 \mathrm{HIV}$-infected individuals screened [28] and has been especially effective in areas of high TB incidence [29]. This was our rationale for collecting induced sputum even when history, examination, and chest radiograph were unremarkable. However, only $60 \%$ of those without sputum were able to provide a sample after nebulised hypertonic saline in this setting. In an area of low incidence of TB, a combination of symptoms, previous exposure to TB, previous use of HAART, weight $<60 \mathrm{~kg}$, CD4 count $<250 / \mu \mathrm{l}$ [30], sputum smear and culture with or without an interferon-gamma release assay were the best option. However, we should note that two patients with active TB who denied any symptoms were only investigated further because of a positive immunospot test (Table 3), and therefore would have not been identified by the suggested algorithms. A systematic review of the interferon-gamma release assays in HIV/TB coinfection has noted a sensitivity of $80 \%$ [3].

The rate at which those with a positive immunospot and HIV might develop TB is unknown. The importance of treating latent TB infection in those with HIV infection is suggested by earlier studies with the tuberculin skin test [31]. The interferon-gamma release assays were more accurate than the tuberculin skin test in predicting both progression to active disease and, in those with a negative test, the absence of progression [32]. A recent systematic review has suggested that these tests may be less useful in low or middle-income countries [33]. However, using the 
Table 3 Patients with positive immunospot test with symptoms suggestive of possible TB, abnormal chest radiograph or positive sputum culture

\begin{tabular}{|c|c|c|c|c|c|c|c|c|c|}
\hline Patient & $\begin{array}{l}\text { Country of } \\
\text { origin }\end{array}$ & CD4 (cells/ul) & $\begin{array}{l}\text { Receiving } \\
\text { HAART }\end{array}$ & Clinical features & Chest radiograph & Sputum culture & Other investigations & Treatment & Final diagnosis \\
\hline 1 & Zimbabwe & 413 & Yes & No symptoms & Normal & $\begin{array}{l}\text { Positive } \\
\text { M. tuberculosis - } \\
\text { fully sensitive }\end{array}$ & & 2RHEZ, 4RH & Pulmonary TB \\
\hline 2 & Cameroon & 350 & No & $\begin{array}{l}\text { Posterior cervical } \\
\text { lymphadenopathy }\end{array}$ & Normal & None received & $\begin{array}{l}\text { FNA cervical } \\
\text { lymph node, } \\
\text { culture negative }\end{array}$ & $2 \mathrm{RHZ}$ & LTBI \\
\hline 3 & Turkey & 331 & Yes & $\begin{array}{l}\text { Back pain and spinal } \\
\text { tenderness }\end{array}$ & Normal & None received & MRI spine normal & $6 \mathrm{H}$ & LTBI \\
\hline 4 & Burundi & 843 & No & $\begin{array}{l}\text { Memory problems; } \\
\text { schizoaffective disorder } \\
\text { Recent weight loss }\end{array}$ & Normal & Negative & $\begin{array}{l}\text { MRI brain - } \\
\text { normal }\end{array}$ & $6 \mathrm{RHZ}$ & $\begin{array}{l}\text { Presumed TB } \\
\text { (weight increased } \\
\text { on treatment) }\end{array}$ \\
\hline 5 & Congo & 437 & No & $\begin{array}{l}\text { Weight loss } 7 \text { kg; } \\
\text { anaemia, hypertension }\end{array}$ & $\begin{array}{l}\text { Reported normal, } \\
\text { but review } \\
\text { suggested Left hilar } \\
\text { lymph nodes }\end{array}$ & Negative & $\begin{array}{l}\text { CT scan: } 8 \mathrm{~mm} \\
\text { axillary lymph } \\
\text { nodes; ground } \\
\text { glass shadowing } \\
\text { right paravertebral } \\
\text { region }\end{array}$ & $2 \mathrm{RHZ}$ & LTBI \\
\hline $6^{*}$ & Jamaica & 539 & No & Paranoid schizophrenia & $\begin{array}{l}\text { Large emphysematous } \\
\text { bullae }\end{array}$ & Negative & Inflammatory markers & $6 \mathrm{H}$ & LTBI \\
\hline $7^{*}$ & Nigeria & 402 & Yes & No symptoms & $\begin{array}{l}\text { Blunting of left } \\
\text { costophrenic angle }\end{array}$ & None received & Inflammatory markers & $6 \mathrm{H}$ & LTBI \\
\hline 8 & Kenya & 168 & Yes & No symptoms & $\begin{array}{l}\text { Bronchopneumonia } \\
2 \text { months before; } \\
\text { now normal chest } \\
\text { radiograph }\end{array}$ & Negative & Inflammatory markers & $6 \mathrm{H}$ & LTBI \\
\hline 9 & Angola & 1372 & Yes & $\begin{array}{l}\text { No symptoms; } \\
\text { cardiac murmur }\end{array}$ & $\begin{array}{l}\text { Minor left basal } \\
\text { shadowing - no } \\
\text { evidence of TB }\end{array}$ & Negative & Inflammatory markers & $6 \mathrm{H}$ & LTBI \\
\hline 10 & Uganda & 980 & Yes & No symptoms & $\begin{array}{l}\text { Peribronchial thickening } \\
\text { within the right perihilar } \\
\text { region }\end{array}$ & Negative & $\begin{array}{l}\text { Other investigations } \\
\text { ordered but } \\
\text { not received }\end{array}$ & $6 \mathrm{H}$ & $\begin{array}{l}\text { Isoniazid-resistant } \\
\text { TB } 2 \text { years later }\end{array}$ \\
\hline 11 & UK & 345 & No & Epilepsy & $\begin{array}{l}\text { Left hilum appears } \\
\text { bulky }\end{array}$ & Negative & $\begin{array}{l}\text { CXR at } 6 \text { months } \\
\text { no change }\end{array}$ & $3 \mathrm{RH}$ & LTBI \\
\hline 12 & Guinea Bissau & 1028 & Yes & $\begin{array}{l}\text { Chest pain? } \\
\text { pericarditis }\end{array}$ & $\begin{array}{l}\text { Blunting left } \\
\text { costophrenic angle }\end{array}$ & Negative & Normal echocardiogram & $6 \mathrm{H}$ & LTBI \\
\hline 13 & Nigeria & 414 & Yes & $\begin{array}{l}\text { Chronic cough; } \\
\text { inguinal lymph } \\
\text { nodes (follicular } \\
\text { hyperplasia) }\end{array}$ & $\begin{array}{l}\text { Right paratracheal } \\
\text { region abnormal } \\
\text { and right hilum. } \\
\text { Reviewed by } \\
\text { radiology team and } \\
\text { considered normal }\end{array}$ & Negative & Inflammatory markers & $6 \mathrm{H}$ & LTBI \\
\hline
\end{tabular}


Table 3 Patients with positive immunospot test with symptoms suggestive of possible TB, abnormal chest radiograph or positive sputum culture (Continued)

\begin{tabular}{|c|c|c|c|c|c|c|c|c|c|}
\hline 14 & Zambia & 829 & Yes & General aches & $2 \mathrm{~cm}$ lung nodule & Negative & $\begin{array}{l}\text { Vitamin D levels } \\
\text { low }\end{array}$ & $6 \mathrm{H}$ & LTBI \\
\hline 15 & Ghana & 122 & Yes & $\begin{array}{l}\text { Fevers and sweats } \\
\text { for } 7 \text { months } \\
\text { (previously denied } \\
\text { any symptoms) }\end{array}$ & $\begin{array}{l}1 \mathrm{~cm} \text { nodule medial } \\
\text { to left superior } \\
\text { pulmonary vein } \\
\text { with blunting left } \\
\text { costophrenic angle }\end{array}$ & $\begin{array}{l}\text { Positive } \\
\text { M. tuberculosis } \\
\text { isolated - fully } \\
\text { sensitive }\end{array}$ & $\begin{array}{l}\text { CT scan - } \\
\text { extensive cervical } \\
\text { lympadenopathy, left } \\
\text { upper zone } \\
\text { infiltration and } \\
\text { splenomegaly, FNA - TB }\end{array}$ & 2RHEZ, 4RH & $\begin{array}{l}\text { Pulmonary and } \\
\text { lymph node TB }\end{array}$ \\
\hline
\end{tabular}

*Borderline results as defined by the CDC, United States [4].

HAART, antiretroviral therapy; TB, tuberculosis; CXR, chest radiograph; LTBI, latent tuberculosis infection; FNA, fine needle aspirate; MRI, magnetic resonance imaging; CT, computerised tomography.

All patients had a chest radiograph and were offered induced sputum for mycobacterial culture in addition to inflammatory markers.

Drug regimens are abbreviated to the number of months of treatment, followed by letters for the drugs administered: $H$, isoniazid; $R$, rifampicin or rifabutin; $Z$, pyrazinamide; $E$, ethambutol. 
less sensitive tuberculin skin test in a low TB incidence country (United States), the rate of reactivation was 2.3 per 100 person years in HIV-infected individuals compared to 0.070 per 100 person years in those without HIV infection [34]. The WHO recommends that national HIV programs should provide TB preventive treatment for HIV-infected individuals with LTBI, provided that active TB has been excluded [1]. HAART significantly reduces the likelihood of $\mathrm{TB}$ in populations that have been exposed to infection [35].

Treatment of LTBI with isoniazid monotherapy in HIV-infected patients reduces the incidence of active TB in individuals both on and off antiretroviral therapy $[15,36]$. The optimum duration of isoniazid is debated but the WHO recommends six months, which is a tradeoff between efficacy and expected completion rates [37]. In our study, patients not on HAART were offered three months isoniazid plus rifampicin, which is equivalent to 6-12 months isoniazid in terms of efficacy and safety $[38,39]$. Preventive treatment was acceptable to patients in our study, with an uptake of $90 \%$ and adherence of 95\% among those who started therapy. This is considerably better than reported completion rates of $45 \%$ in New York City [40], and 54\% in LTBI treated TB contacts in the same area of London [16] and suggests that in this population, isoniazid preventive therapy fulfils the requirements set for its implementation [41].

Isoniazid-resistant $\mathrm{TB}$ occurred in one patient within two years of completing preventive treatment with isoniazid monotherapy. It is not known whether resistance was present in the original latent strain, or developed during preventive treatment, or whether the patient was newly infected with a resistant TB strain. Concerns have been expressed regarding the possibility that the use of isoniazid monotherapy in preventive treatment might increase the risk of isoniazid resistant strains of TB if the disease develops subsequently. However, a systematic review reported an overall relative risk of 1.45 (CI 0.85-2.47) comparing isoniazid-resistant strains in those given preventive treatment and placebo controls [42]. The results were the same when studies of HIV-infected and HIVuninfected people were considered separately. Recent data from South Africa show that TB developing after recent isoniazid preventive therapy has a prevalence of drug resistance similar to background levels [36]. However, in vitro experiments have suggested that isoniazid resistance is more likely due to the use of the drug [43] and that the rate of mutation in latent TB may be the same as in active disease [44]. The latter paper recommends the use of a two-drug regimen for preventive treatment $[31,38]$.

\section{Conclusions}

Screening for TB in those with HIV infection and without symptoms in London (UK) yielded approximately $10 \%$ with latent infection and $1 \%$ with active disease.
This yield of latent and active TB was greater than typically found in contact tracing, which should encourage health care workers to implement IGRA-based TB screening in the HIV clinic. There was a high completion rate for preventive treatment in those with a positive test result, and follow up of treated individuals will provide valuable insights into the long-term effects of preventive treatment.

\section{Competing interests}

The author declare that they have no competing interest.

\section{Acknowledgement}

These data were presented in part at the 14th Annual Conference of the British HIV Association, April 2008 and published abstracts in HIV Medicine, Volume 9, Supplement 1, May 2008, pages 29 and 37.

\section{Author details}

${ }^{1}$ Department of Sexual Health, Homerton University Hospital, Homerton Row, London E9 6SR, United Kingdom. ${ }^{2}$ Department of Microbiology, Homerton University Hospital, Homerton Row, London E9 6SR, United Kingdom. ${ }^{3}$ Department of Respiratory Medicine, Homerton University Hospital, Homerton Row, London E9 6SR, United Kingdom. ${ }^{4}$ HIV and STI Department, Health Protection Services - Colindale, Health Protection Agency, 61 Colindale Avenue, London NW9 5EQ, United Kingdom.

\section{Authors' contributions}

MK, NG and $A B$ entered patients into the study. MK, KC and GB drafted the manuscript. $A A$ carried out the immunoassays. $G B, A B$ and $J A$ cooperated in the design of the study. MK performed the statistical analysis. $G B$ and $A B$ conceived the study, and participated in its design and coordination with $I R$ KC and JA. GB obtained the funding for the study. All authors read and approved the final manuscript.

\section{Funding}

UK Department of Health grant obtained through the North East London Tuberculosis Network.

Received: 10 October 2011 Accepted: 4 May 2012

Published: 4 May 2012

\section{References}

1. $\mathrm{WHO}$ and UNAIDS: Policy statement on preventive therapy against tuberculosis in people living with HIV. Geneva, Switzerland: WHO; 1998.

2. World Health Organization: Guidelines for intensified tuberculosis case-finding and isoniazid preventive therapy for people living with HIV in resource constrained settings. Geneva, Switzerland: Department of HIV/AIDS, Stop TB Department, World Health Organization; 2010.

3. Sester M, Sotgiu G, Lange C, Giehl C, Girardi E, Migliori GB, Bossink A, Dheda K, Diel R, Dominguez J, Lipman M, Nemeth J, Ravn P, Winkler S, Huitric E, Sandgren A, Manissero D: Interferon-gamma release assays for the diagnosis of active tuberculosis: a systematic review and meta-analysis. Eur Respir J 2011, 37:100-111.

4. Mazurek GH, Jereb J, Vernon A, LoBue P, Goldberg S, Castro K: Updated guidelines for using interferon-gamma release assays to detect Mycobacterium tuberculosis infection - United States 2010. MMWR 2011, 59(RR05):1-25.

5. Pozniak AL, Collins S, Coyne KM, on behalf of the British HIV Association guidelines subcommittee: BHIVA guidelines for the treatment of TB/HIV Co-infection 2010. London, UK: BHIVA; 2011.

6. Aichelburg MC, Rieger A, Breitenecker F, Pfiztershammer K, Tittes J, Eltz S, Aichelburg AC, Stingl G, Makristathis A, Kohrgruber N: Detection and prediction of active tuberculosis disease by a whole-blood interferon-gamma release assay in HIV-1-infected individuals. Clin Infect Dis 2009, 48(7):954-962.

7. Stephan C, Wolf T, Goetsch U, Bellinger O, Nisius G, Oremek G, Rakus Z, Gottschalk R, Stark S, Brodt HR, Staszewski S: Comparing QuantiFERON-tuberculosis gold, T-SPOT tuberculosis and tuberculin skin test in HIV-infected individuals from a low prevalence tuberculosis country. AIDS 2008, 22:2471-2479. 
8. Talati NJ, Seybold U, Humphrey B, Aina A, Tapia J, Weinfurter P, Albalak R Blumberg HM: Poor concordance between interferon-ganna release assays and tuberculin skin tests in diagnosis of latent tuberculosis infection among HIV-infected individuals. BMC Infect Dis 2009, 9:15.

9. Health Protection Agency: HIV in the United Kingdom: 2010 Report. London, UK: HPA; 2010

10. Health Protection Agency: Tuberculosis in the UK: Annual report on tuberculosis surveillance in the UK 2010. London, UK: HPA: 2010.

11. World Health Organization: Global Tuberculosis Control: WHO Report 2010. Geneva, Switzerland: WHO; 2010.

12. Garrett N, Kall M, Ashcroft T, Reeves I, Anderson J, Bothamley G: Evaluation of HIV-infected patients for latent or subclinical tuberculosis with the T-Spot.TB (Elispot) test. HIV Med 2008, 9(Suppl 1):30.

13. Getahun $H$, Kittikraisak W, Heilig CM, et al: Development of a standardized screening rule for tuberculosis in people living with HIV in resource constrained settings: individual participant data meta-analysis of observational studies. PLoS Med 2011, 8(1):e1000391.

14. National Institute for Health and Clinical Excellence (NICE): Tuberculosis: clinical diagnosis and management of tuberculosis, and measures for its prevention and control. London, UK: Royal College of Physicians; 2006.

15. Akolo C, Adetifa I, Shepperd S, Volmink J: Treatment of latent tuberculosis in HIV infected persons. Cochrane Database Syst Rev 2010, 1:CD000171.

16. Rennie TW, Bothamley GH, Engova D, Bates IP: Patient choice promotes adherence in preventive treatment for latent tuberculosis. Eur Respir $\mathrm{J}$ 2007, 30:728-735.

17. Gordin F, Chaisson RE, Matts JP, Miller C, de Lourdes Garcia M, Hafner R, Valdespino JL, Coberty J, Schecter M, Klukowicz AJ, Barry MA, O'Brien RJ: Rifampin and pyrazinamide versus isoniazid for the prevention of tuberculosis in HIV-infected persons: an international randomized trial. JAMA 2000, 283:1445-1450.

18. van Hest $R$, Baars $H$, Kik S, van Gerven $P$, Trompenaars MC, Kalisvaart M, Keizer S, Borgdorff M, Mensen M, Cobelens F: Hepatotoxicity of rifampinpyrazinamide and isoniazid preventive therapy and tuberculosis treatment. Clin Infect Dis 2004, 39:488-496.

19. Pulido F, Peňa JM, Rubio R, Moreno S, González J, Guijarro C, Costa JR, Vázques JJ: Relapse of tuberculosis after treatment in human immunodeficiency virus-infected patients. Ann Intern Med 1997, 157: 227-232.

20. National Institute for Health and Clinical Excellence (NICE): Tuberculosis: clinical diagnosis and management of tuberculosis, and measures for its prevention and control. London, UK: Royal College of Physicians; 2011

21. Reid MJA, Shah NS: Approaches to tuberculosis screening and diagnosis in people with HIV in resource limited settings. Lancet Infect Dis 2009, 9:173-184.

22. Cain KP, McCarthy KD, Heilig CM, Monkongdee P, Tasaneeyapan T, Kanara N, Kimerling ME, Chheng P, Thai S, Sar B, Pharuphak P, Teeratakulpisam N, Phanuphak N, Dung NH, Quy HT, That LH, Varma JK: An algorithm for tuberculosis screening and diagnosis in people with HIV. N Engl J Med 2010, 362:707-716.

23. Corbett EL, Bandason T, Cheung YB, Munyatta S, Godfrey-Fausett P, Hayes R, Churchyard G, Butterworth A, Mason P: Epidemiology of tuberculosis in a high HIV prevalence population provided with enhanced diagnosis of symptomatic disease. PLoS Med 2007, 4(1):e22

24. Wood R, Middelkoop K, Myer L, Grant AD, Whitelaw A, Lawn SD, Kaplan G, Huebner R, McIntyre J, Bekker L-G: Undiagnosed tuberculosis in a community with high HIV prevalence: implications for tuberculosis control. Am J Respir Crit Care Med 2007, 175(1):87-93.

25. Greenberg SD, Frager D, Suster B, Walker S, Stavropoulos C, Rothpearl A Active pulmonary tuberculosis in patients with AIDS: spectrum of radiographic findings (including a normal appearance). Radiology 1994 193(1):115-119.

26. Hargreaves NJ, Kadzakumanja O, Phiri S, Nyangulu DS, Salaniponi FML, Harries AD, Squire SB: What causes smear-negative pulmonary tuberculosis in Malawi, an area of high HIV seroprevalence? Int J Tuberc Lung Dis 2001, 5(2):113-122.

27. Mtei L, Matee M, Herfort O, Bakari M, Horsburgh CR, Waddell R, Cole BF, Vuola JM, Tvaroha S, Kreisworth B, Pallangyo K, von Reyn CF: High rates of clinical and subclinical tuberculosis among HIV-infected ambulatory subjects in Tanzania. Clin Infect Dis 2005, 40(10):1500-1507.

28. Kranzer K, Houben RM, Glynn JR, Bekker LG, Wood R, Lawn SD: Yield of HIV-associated tuberculosis during intensified case finding in resource-limited settings: a systematic review and meta-analysis. Lancet Infect Dis 2010, 10(2):93-102.

29. Bassett IV, Wang B, Chetty S, et al: Intensive tuberculosis screening for HIVinfected patients starting antiretroviral therapy in Durban, South Africa. Clin Infect Dis 2010, 51(7):823-829.

30. Rangaka MX, Gideon HP, Wilkisnon KA, Pai M, Mwansa-Kambafilwe J, Maartens G, Glynn JR, Boulle A, Fielding K, Goliath R, Titus R, Mathee S, Wilkinson RJ: No discriminatory value of interferon-gamma release assays added to smear negative HIV-tuberculosis algorithms. Eur Respir J 2012, 39(1):163-171.

31. Volmink J, Woldehanna S: Treatment of latent tuberculosis infection in HIV infected persons. Cochrane Database Syst Rev 2004, CD000171. doi:10.1002/14651858.CD0000171.pub2.

32. Diel R, Goletti D, Ferrara C, Bothamley G, Cirillo D, Kampmann B, Lange C, Losi M, Markova R, Migliori GB, Nienhaus A, Ruhwald M, Wagner D, Zellweger J-P, Sandgren A, Manissero D: Interferon-gamma release assays for the diagnosis of latent Mycobacterium tuberculosis infection: a systematic review and meta-analysis. Eur Respir J 2010, 37:88-99.

33. Cattamanchi A, Smith R, Steingert KR, Metcalfe JZ, Date A, Coleman C, Marston BJ, Huang L, Hopewell PC, Pai M: Interferon-gamma release assays for the diagnosis of latent tuberculosis infection in HIV-infected individuals: a systematic review and meta-analysis. J Acquir Immune Defic Syndr 2011, 56:230-238.

34. Horsburgh CR Jr, O'Donnell M, Chamblee S, Moreland JL, Johnson J, Marsh BJ, Narita M, Johnson LS, von Reyn CF: Revisiting rates of reactivation tuberculosis: a population-based approach. Am J Respir Crit Care Med 2010, 182(3):420-425

35. United Kingdom Collaborative HIV Cohort Study Group: Tuberculosis among people with HIV infection in the United Kingdom: opportunities for prevention? AIDS 2009, 23(18):2507-2515.

36. van Halsema CL, Fielding KL, Chihota VN, Russell EC, Lewis JJ, Churchyard GJ, Grant AD: Tuberculosis outcomes and drug susceptibility in individuals exposed to isoniazid preventive therapy in a high HIV prevalence setting. AIDS 2010, 24(7):1051-1055.

37. Landry J, Menzies D: Preventive chemotherapy. Where has it got us? Where to go next? Int J Tuberc Lung Dis 2008, 12(12):1352-1364.

38. Ena J, Valls V: Short-course therapy with rifampin plus isoniazid, compared with standard therapy with isoniazid, for latent tuberculosis infection: a meta-analysis. Clin Infect Dis 2005, 40(5):670-676.

39. Sterling TR, Villarino ME, Borison AS, Shang N, Gordin F, Bliven-Sizemore E, Hackman J, Hamilton CD, Menzies D, Kerrigan A, Weis SE, Weiner M, Wing D, Conde MB, Bozeman L, Horsburgh CR, Chaisson RE, for the TB Trials Consortium PREVENT TB Study Team: Three months of rifapentine and isoniazid for latent tuberculosis infection. New Engl J Med 2011, 365: 2155-2166.

40. Li J, Munsiff SS, Tarantino T, Dorsinville M: Adherence to treatment of latent tuberculosis infection in a clinical population in New York City. Int J Infect Dis 2010, 14(4):e292-e297.

41. Aït-Khaled N, Alarcon E, Bissell K, et al: Isoniazid preventive therapy for people living with HIV: public health challenges and implementation issues. Int J Tuberc Lung Dis 2009, 13(8):927-935.

42. Balcells ME, Thomas SL, Godfrey-Faussett P, Grant AD: Isoniazid preventive therapy and risk for resistant tuberculosis. Emerg Infect Dis 2006, 12 (5):744-751.

43. Bergval IL, Schuitema AR, Klatser PR, Anthony RM: Resistant mutants of Mycobacterium tuberculosis selected in vitro do not reflect the in vivo mechanism of isoniazid resistance. J Antimicrob Chemother 2009, 64: 515-523.

44. Ford CB, Lin PL, Chase MR, Shah RR, lartchouk O, Galagan J, Mohaideen N, loerger TR, Sacchettini JC, Lipsitch M, Flynn JL, Fortune SM: Use of whole genome sequencing to estimate the mutation rate of Mycobacterium tuberculosis during latent infection. Nat Genet 2011, 43:482-486.

doi:10.1186/1471-2334-12-107

Cite this article as: Kall et al.: Latent and subclinical tuberculosis in HIV infected patients: a cross-sectional study. BMC Infectious Diseases 2012 $12: 107$ 